\title{
Effects of Different Carotenoids on Pigmentation of Blood Parrot (Cichlasoma synspilum $\times$ Cichlasoma citrinellum)
}

\author{
Tieliang Li ${ }^{1}$, Chuan $\mathrm{He}^{2}$, Zhihong Ma ${ }^{1}$, Wei Xing ${ }^{1}$, Na Jiang ${ }^{1}$, Wentong Li ${ }^{1}$, Xiangjun Sun ${ }^{1}$ and Lin Luo ${ }^{1 *}$
}

Beijing Fisheries Research Institute, Beijing Key Laboratory of Fishery Biotechnology, Beijing, PR China

${ }^{2}$ Extension Stations of Aquiculture Technology, Beijing Municipal Bureau of Agriculture, Beijing, PR China

\begin{abstract}
A feeding experiment was carried out to determine the effects of dietary carotenoid source on body color, skin and scale pigmentation, antioxidant responses of blood parrot (Cichlasoma synspilum $+\times$ Cichlasoma citrinellum 3). Seven experimental diets were formulated as following: the control diet without carotenoids; PO diet with $4.0 \mathrm{~g} / \mathrm{kg}$ paprika oleoresin, HP diet with $2.0 \mathrm{~g} / \mathrm{kg}$ Haematococcus pluvialis, PR diet with $2.0 \mathrm{~g} / \mathrm{kg}$ Phaffia rhodozyma, AS diet with $0.4 \mathrm{~g} / \mathrm{kg}$ synthetic astaxanthin, CA diet with $1.0 \mathrm{~g} / \mathrm{kg} \beta$-carotene and POL diet with $2.0 \mathrm{~g} / \mathrm{kg}$ paprika oleoresin + $3.0 \mathrm{~g} / \mathrm{kg}$ lutein. Each experimental diet was fed to triplicate groups of fish to visual satiation twice per day for 8 weeks.

The results showed that AS diet turn fish body red higher and sooner, followed by PR diet and HP diet, successively $(P<0.05)$. PO and CA had no significant effect on improving body color, but POL diet can turn fish color yellow effectively $(P<0.05)$. Astaxanthin concentration in diet is positively correlated with redness $a^{*}$, but negatively with lightness $L^{*}$. Dietary lutein is positive linear correlation with yellowness $b^{*}$. All carotenoids can significantly reduce plasma superoxide dismutase (SOD), glutathione peroxidase (GSH-Px), and lipid peroxide (LPO) level, but increase total antioxidant capacity (T-AOC). The present results suggest that dietary inclusion of $0.4 \mathrm{~g} / \mathrm{kg}$ synthetic astaxanthin can improve body color effectively and quickly, and all test carotenoid source can increase antioxidant activities of blood parrot.
\end{abstract}

Keywords: Blood parrot (Cichlasoma synspilum $q \times$ Cichlasoma citrinellum ठิ); Carotenoids; Pigmentation; Antioxidant capacity

\section{Introduction}

Blood parrot (Cichlasoma synspilum $\bigcirc \times$ Cichlasoma citrinellum $\left.{ }^{7}\right)$ is one of the most popular ornamental fish in China. It has bright red appearance and plump body. It is well known that in addition to body shape and size, body color is one of the most important quality criteria setting the market value of blood parrot [1]. Like other animals, fish are unable to perform de novo synthesis of caroteniods [2]. Fish use oxygenated carotenoids, one of the most important groups of natural pigments, for pigmentation of skin and flesh. Under intensive farming conditions and aquarium rearing, blood parrot will be color fading when they are fed exclusively on artificial diets without pigments. It is therefore necessary to study the suitable pigment additives for blood parrot. Commonly used carotenoids in fish feed include synthetic $\beta$-carotene, astaxanthin, cantaxanthin, zeaxanthin and lutein and natural sources of yeast, bacteria, algae, higher plants and crustacean meal $[3,4]$. For example, synthetic astaxanthin has been used to increase the skin coloration of blood parrot [1]. In order to use carotenoids additive suitable for blood parrot commercially on a large scale, different source of carotenoids should be studied. Natural astaxanthin extracted from the algae Chlorella vulgaris has been used to increase the skin coloration of goldfish, Carassius auratus [5]. Lutein, found naturally in marigold meal, is also an effective pigment for inducing the orange coloration of goldfish [6] and is now used commercially in ornamental fish food. An esterified source of astaxanthin from Haematococcus pluvialis increased the natural reddish hue of the skin of red porgy (Pagrus pagrus) better than Carophyll Pink [7]. These carotenoids might have potential to be used at color improvement of blood parrot.

On the other hand, it had been reported that carotenoids can protect the body against oxidative damage [8]. Dietary astaxanthin has shown to enhance antioxidant status in Atlantic salmon Salmo salar and improve their health [9]. Dietary astaxanthin has shown to enhance antioxidant status in prawn and increase its resistance to various environmental stresses [10].Therefore, besides the function of pigmentation improvement, carotenoids may increase antioxidants capabilities. A relationship between different carotenoids sources and antioxidant status in blood parrot should be evaluated.

Taking all above into account, one main purpose of the present study was to evaluate the effectiveness of different carotenoids sources such as the algae $H$. pluvialis, artificial synthesis astaxanthin, Pphaffia rhodozyma, lutein from Tagetes erecta, paprika oleoresin, and $\beta$ carotene in dietary with recommended concentrations, to appropriately develop a pigment for blood parrot body color. We aimed to determine the value of skin color chroma and the total carotenoid contents in skin and scales, to elucidate what kinds of dietary carotenoids are metabolically transformed in the skin of blood parrot. Given the important role of carotenoids in fish antioxidation, another purpose of the present work was to check whether dietary carotenoids would affect antioxidant capacity of blood parrot.

\section{Materials and Methods}

\section{Experimental diets}

A basal diet, containing $324 \mathrm{~g} / \mathrm{kg}$ crude protein and $57 \mathrm{~g} / \mathrm{kg}$ crude lipid, was composed of American white fishmeal $120 \mathrm{~g} / \mathrm{kg}$, soybean

*Corresponding author: Lin Luo, Beijing Fisheries Research Institute, Beijing 100068, PR China, Tel: 8610-67588781; E-mail: Iuo_lin666@sina.com

Received December 31, 2015; Accepted February 04, 2016; Published February 08, 2016

Citation: Li T, He C, Ma Z, Xing W, Jiang N, et al. (2016) Effects of Different Carotenoids on Pigmentation of Blood Parrot (Cichlasoma synspilum $\times$ Cichlasoma citrinellum). J Aquac Res Development. 7: 414. doi:10.4172/2155-9546.1000414

Copyright: (c) $2016 \mathrm{Li} \mathrm{T}$, et al. This is an open-access article distributed under the terms of the Creative Commons Attribution License, which permits unrestricted use, distribution, and reproduction in any medium, provided the original author and source are credited. 
meal $300 \mathrm{~g} / \mathrm{kg}$, degossypolled cottonseed meal $120 \mathrm{~g} / \mathrm{kg}$, soybean oil 30 $\mathrm{g} / \mathrm{kg}$, wheat flour $200 \mathrm{~g} / \mathrm{kg}$, wheat middling $200 \mathrm{~g} / \mathrm{kg}$, vitamin premix $10 \mathrm{~g} / \mathrm{kg}$, and mineral premix $200 \mathrm{~g} / \mathrm{kg}$. Using this basal mixture, six pigmented diets were formulated by added pigments in accordance with recommended doses by the supplier. Diet $\mathrm{PO}$ contains $4 \mathrm{~g}$ paprika oleoresin/kg feed; diet HP contains $2 \mathrm{~g}$ algae $H$. pluvialis/kg feed; diet PR contains $2 \mathrm{~g}$ P. rhodozyma $/ \mathrm{kg}$ feed; diet AS contains $0.4 \mathrm{~g}$ astaxanthin $/ \mathrm{kg}$ feed; diet CA contains $1 \mathrm{~g} \beta$-carotene $/ \mathrm{kg}$ feed; and diet POL contains $4 \mathrm{~g}$ paprika oleoresin $/ \mathrm{kg}$ feed and $3 \mathrm{~g}$ lutein $/ \mathrm{kg}$ feed. The ingredient and proximate analyses of the diets were shown in Table 1. The pigment materials were mixed with the basal diets completely and the experimental diets were made into floating extruded pellets $(\varnothing 2.0 \mathrm{~mm})$ by TSE65S model twin screw steam extruder (Beijing Modern Yanggong Machinery S\&T Development Co., Ltd, China). All diets were stored at $-20^{\circ} \mathrm{C}$ to avoid oxidation of the pigmentations throughout the experiment.

\section{Fish and rearing conditions}

The homogeneous blood parrots were obtained from a commercial fish farm at Tianjin, China. Prior to the beginning of the experiment, fish were fed the control diet 2 weeks for acclimatization in laboratory culturing system. Hatchery reared fish, at roughly the same total body length of $10 \mathrm{~cm}$, were randomly distributed into twenty-one groups of 30 fish each (seven treatments, with triplicate each) at the beginning of the test. The fish were cultivated in an aquarium measuring $90 \mathrm{~cm} \times 40$ $\mathrm{cm} \times 50 \mathrm{~cm}$ and supplied with continuous aeration. The oxygen level was kept at $7.3 \pm 0.1 \mathrm{mg} / \mathrm{L}$. The water was changed three times weekly. One-third of the water was changed each time. The water temperature was $26 \pm 1^{\circ} \mathrm{C}$. The fish were satiation hand-fed twice daily at 10:00 and 16:00. The fish were subjected to a natural photoperiod during 56 days experimental period.

\section{Biochemical and colour analysis}

Feed analysis: Biochemical analysis of feed was conducted in triplicate according to AOAC (2005). Briefly, crude protein $(\mathrm{N} \times 6.25)$ was determined by the Kjeldahl method after acid digestion using an Auto Kjeldahl System (2100-Auto-analyzer, Foss, Hillerød, Denmark). Crude lipid was determined by the ether extraction method using a Soxtec System HT (Soxtec System HT6, Foss, Hillerød, Denmark). Moisture was determined by oven-drying at $105^{\circ} \mathrm{C}$ for $24 \mathrm{~h}$. Ash was determined by combustion at $550^{\circ} \mathrm{C}$ for $12 \mathrm{~h}$.

Colour parameters analysis: From the beginning to the end of the trial, three fish of each treatment were taken randomly to determined skin color every week. Photos were taken every two weeks to record the change of body color. As an ornamental fish, blood parrots need simple, rapid and accurate color analysis alive. Fishes were individually measured for skin color using a Minolta CM-600 Chroma Meter (Minolta Camera Co. Ltd., Asaka, Japan) before commencement of the feeding trial to establish baseline measurements (week 0) and then every week for the 8 -week period. The Chroma Meter was set to take absolute measurements in the $L^{*}, a^{*}$, and $b^{*}$ measuring mode (CIE1976) using D65 illuminant. Color measurements were taken in the centre of the lateral body. $L^{*}$ is the lightness variable where $L^{*}=$ 100 is white and $L^{*}=0$ is black; $a^{*}$ is the red chromaticity coordinates where $+a^{\star}$ stands for red and $-a^{\star}$ stands for green, and $b^{*}$ is the yellow chromaticity coordinates where $+b^{*}$ stands for yellow and $-b^{*}$ stands for blue. To avoid the influence of day time on day body color, $L^{*}, a^{*}$, and $b^{\star}$ measurements were always done at 14:00 every time.

Analysis of carotenoids in feed, fish flesh, skin and scales: $\beta$-carotene, zeaxanthin, lutein and astaxanthin content from feed, skin, scale and flesh samples were obtained according to the following high performance liquid chromatography (HPLC) method: 1 . Feed, flesh, skin or scale samples $(1 \mathrm{~g})$ was taken into a $250 \mathrm{~mL}$ Erlenmeyer flask individually and mixed with $30 \mathrm{~mL}$ ethanol, $5 \mathrm{~mL} \mathrm{10 \%} \mathrm{(mass/volume)}$ ascorbic acid, $10 \mathrm{~mL} 50 \%$ (mass/volume) $\mathrm{KOH}$. The mixture solution was heated and recycled in Hotplate Stirrer for Round-Bottom-Flasks for 30 mins, then cooled by putting the flasks into the cold water. 2. All above saponated mixture solution were taken into separating funnel and washed by $100 \mathrm{~mL}$ petroleum ether; then the separating funnel was shaken 3 min twice; water in the separating funnel was removed after the mixture solution layering. 3. Anhydrous sodium sulfate was added into the separating funnel, and then the filtrate was collected and vacuum drying. Dried sample was added an appropriate amount of mobile phase solution and then filtered through a $0.2 \mu \mathrm{m}$ Millipore filter and stored in $4 \mathrm{~mL}$ brown vials. 4 . Identification of carotenoid was accomplished by HPLC with standards. The volume of the solution was recorded at $448 \mathrm{~nm}$ by HPLC to calculate the $\beta$-carotene, zeaxanthin and lutein concentration, $470 \mathrm{~nm}$ to astaxanthin concentration.

The carotenoid concentration was calculated according to the formula:

$$
\mathrm{X}(\mu \mathrm{g} / 100 \mathrm{~g})=(\mathrm{C} \times \mathrm{V}) /(\mathrm{m} \times 100)
$$

Total carotenoids concentration $(\mathrm{mg} / \mathrm{kg})=\mathrm{X}(\beta$-carotene $)+\mathrm{X}$ (zeaxanthin) $+\mathrm{X}$ (lutein) $+\mathrm{X}$ (astaxanthin)

Where $\mathrm{X}$ is carotenoid monomer concentration $(\mathrm{mg} / \mathrm{kg})$; $\mathrm{C}$ is carotenoid monomer concentration in sample solution $(\mu \mathrm{g} / \mathrm{mL}) ; \mathrm{V}$ is final constant volume of concentrate solution $(\mathrm{mL}) ; \mathrm{m}$ is the sample weight $(\mathrm{g})$.

\section{Analysis of antioxidant parameters}

At the end of feeding trial, blood samples were withdrawn from the caudal vein of three fish randomly taken from each aquarium using sterile syringes. Blood samples were prepared by mixing $14 \mu \mathrm{L}$ heparinized solution containing $0.14 \mathrm{mg}$ heparin sodium with $700 \mu \mathrm{L}$ blood immediately after withdrawing the blood. The

\begin{tabular}{|c|c|c|c|c|c|c|c|}
\hline & PO & HP & PR & AS & CA & POL & The control \\
\hline Moisture (\%) & 89.1 & 89.3 & 89.3 & 89.5 & 89.4 & 88.9 & 89.5 \\
\hline Curde protein (\%) & 32.4 & 32.5 & 32.5 & 32.5 & 32.5 & 32.3 & 32.5 \\
\hline Crude fat (\%) & 5.7 & 5.7 & 5.7 & 5.7 & 5.7 & 5.7 & 5.7 \\
\hline Ash (\%) & 8.2 & 8.2 & 8.2 & 8.3 & 8.2 & 8.2 & 8.3 \\
\hline$\beta$-carotene $(\mathrm{mg} / \mathrm{kg})$ & 60.7 & 15.4 & 186.3 & 2.6 & 5449 & 47.7 & 2.4 \\
\hline Lutein $(\mu \mathrm{g} / 100 \mathrm{~g})$ & 362 & 99.2 & 61.4 & 51.9 & 22.5 & 776 & 21.7 \\
\hline Zeaxanthin $(\mu \mathrm{g} / 100 \mathrm{~g})$ & 260 & 27.5 & 26.8 & 22.5 & 7.47 & 152.2 & 8.8 \\
\hline Astaxanthin $(\mu \mathrm{g} / 100 \mathrm{~g})$ & 79.8 & 1065.2 & 1493.7 & 2076.4 & 59.8 & 88.4 & 5.2 \\
\hline Total carotenoid $(\mu \mathrm{g} / 100 \mathrm{~g})$ & 762.5 & 1207.3 & 1768.2 & 2153.4 & 5539 & 1064.3 & 38.1 \\
\hline
\end{tabular}

Table 1: Proximate analysis of the experimental diets. 
samples were chilled at $-80^{\circ} \mathrm{C}$ until being used for determination of Superoxide Dismutase (SOD), glutathione peroxidase (GSH-Px), total antioxidant capacity (T-AOC), and lipid peroxide (LPO). The different antioxidant parameters of SOD, GSH-Px, T-AOC and LPO were analyzed using Randox Laboratories kits (Crumlin, Co. Atrim, UK) by spectrophotometry (U-2000; Hitachi Ltd., Japan).

\section{Statistical analysis}

All data were subjected to a one-way analysis of variance (ANOVA) using the Statistica 7.0 software environment to test the effects of the experimental diets. All of the results are expressed as the means \pm S.E.M. Duncan's test was used to test differences among the individual means. The differences were regarded as significant when $P<0.05$. The slopes of color parameters and scale and skin pigment responses to the diets were compared after fitting a linear regression model. Correlations were regarded as significant when the correlation coefficient $R>0.5$.

\section{Results}

\section{Effects of experimental diets on the body color}

No mortality was observed during the feeding trial. The changing of lightness $L^{*}$ of blood parrot during 56 days trial was shown in (Figure 1). At the end of the first week, fish fed AS diet had significantly lower lightness than that of fish fed the control diet $(P<005)$. Compared with the rest of fish groups, AS fish group kept the lowest lightness from day 21 until the end of trial $(P<$ 005). Meanwhile, as time went on, the lightness of AS fish group was significantly lower since day 21 compared to the two first weeks $(P<0.05)$. And the lightness of PO fish group was significantly higher since day 42 compared to all the previous weeks $(P<0.05)$. Redness $a^{\star}$ of AS, PR and HP fish group was significantly higher than that of PO, CA, POL and the control fish groups from day 7, 14 and 21 to the end of the trial, respectively $(P<0.05)$ (Figure 2$)$, and redness $a^{*}$ of AS, PR, and HP fish groups order from high to low is AS $>$ PR $>$ HP $(P<0.05)$. On the other hand, redness of AS fish group increased with the days going on and got the highest value at day $56(P<0.05)$. Although redness of PR and HP fish group increased with time going on, they kept the same level from day 35 to $56(P>0.05)$. Redness of PO, CA and POL fish group had no significantly difference with the control group during the whole trial $(\mathrm{P}>0.05)$.

Yellowness $b^{*}$ of POL fish group was significantly higher than that of the rest fish group since 35 days until the end of the trial $(P<0.05)$ (Figure 3).

Visual differences in coloration between diet fish were shown in Figures 3 and 4 . AS fish group was obviously redder than other fish groups, followed by PR and HP fish groups, successively. While POL fish group was obviously yellower. CA and PO fish groups were yellower than the control fish group, but the difference was not much clear.

Table 2 showed regression models of coloration efficacy. Regression analysis revealed that lightness $L^{*}$ of fish body had negative linear relation with diet $(R=-0.53)$ and skin $(R=-0.54)$ astaxanthin levels, while redness $a^{*}$ was significantly positively correlated to diet, skin and scale astaxanthin levels, with $\mathrm{r}$ values of $0.91,0.91$ and 0.85 , respectively. Yellowness $b^{*}$ of fish body positively and linearly related with diet lutein levels $(R=0.52)$.

\section{Carotenoids in fish scale and skin}

Carotenoids concentrations in the scale and skin of blood parrot after being fed for day 56 was shown in Table 3 . $\beta$-carotene concentration in scale of fish fed on HP had not been detected. $\beta$-carotene concentration in scale and skin of fish fed on CA diet were significantly higher than that of the rest fish groups $(P<0.05)$. Lutein and zeaxanthin concentrations in scale and skin of fish fed on POL diet were significantly higher than those of the rest fish groups $(P<0.05)$. AS fish group had the significantly highest astaxanthin concentration in scale and skin, followed by PR fish group, HP fish group, PO, CA and POL fish groups, the control fish group, orderly $(P<0.05)$. POL fish group had the highest total carotenoids in both scale and skin because of their especially higher lutein concentration $(P<0.05)$. PR and AS fish groups had significantly higher total scale carotenoids than $\mathrm{PO}$ and the control fish groups $(P<0.05)$. Total skin carotenoids of all fish groups fed pigment diets were significantly higher than that of the control fish group $(P<0.05)$; total carotenoids in AS and PR fish skin were significantly higher than that in $\mathrm{PO}$ and $\mathrm{HP}$ fish skin $(P<0.05)$;

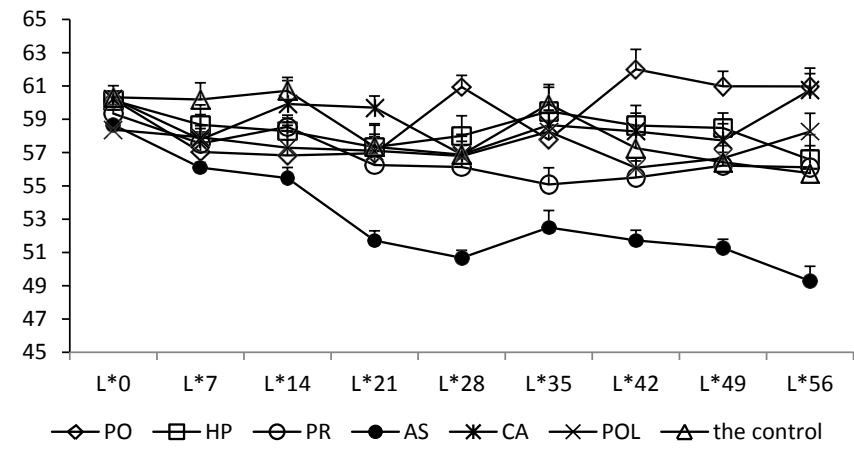

Figure 1: The changing of lightness $\left(L^{*}\right)$ of blood parrot during 56 days trial. Values are mean $+\mathrm{SE}$.

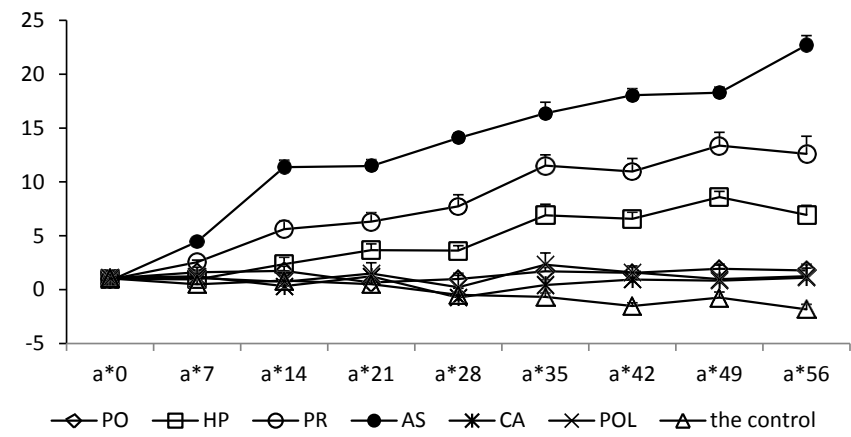

Figure 2: The changing of redness $\left(\mathrm{a}^{*}\right)$ of blood parrot during 56 days trial. Values are mean + SE.

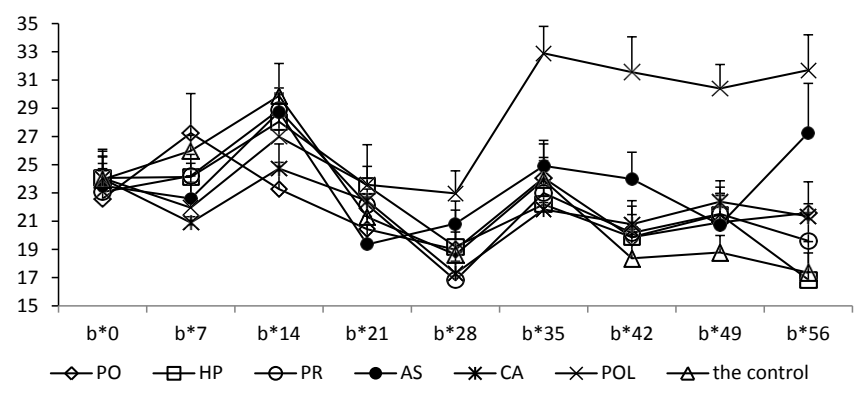

Figure 3: The changing of yellowness $\left(b^{*}\right)$ of blood parrot during 56 days trial. Values are mean $+\mathrm{SE}$. 
Citation: Li T, He C, Ma Z, Xing W, Jiang N, et al. (2016) Effects of Different Carotenoids on Pigmentation of Blood Parrot (Cichlasoma synspilum × Cichlasoma citrinellum). J Aquac Res Development. 7: 414. doi:10.4172/2155-9546.1000414

Page 4 of 7

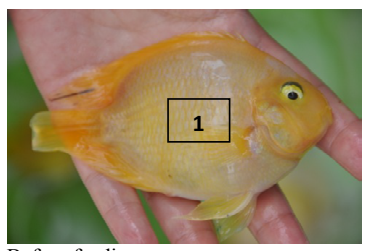

Before feeding

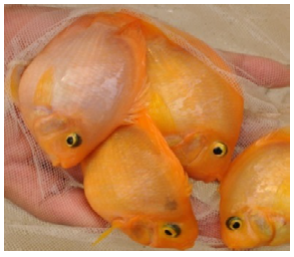

HP
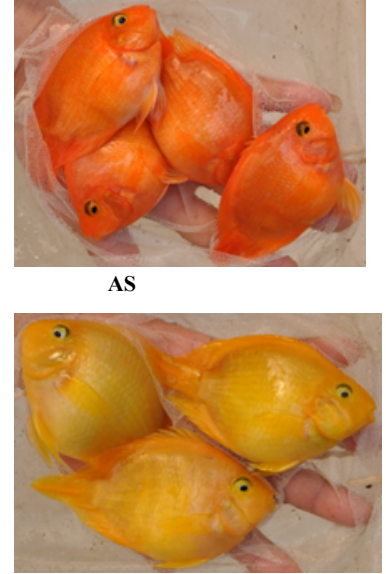

POL

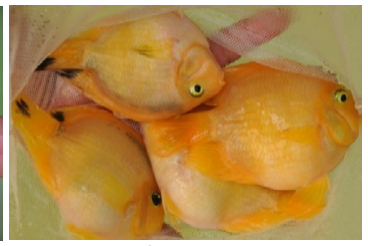

$\mathrm{PO}$

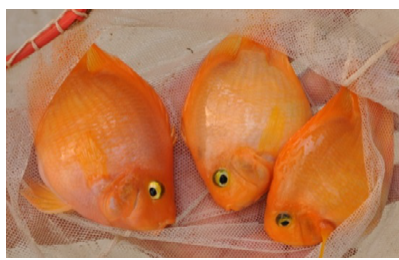

PR

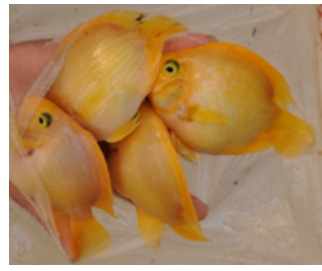

CA

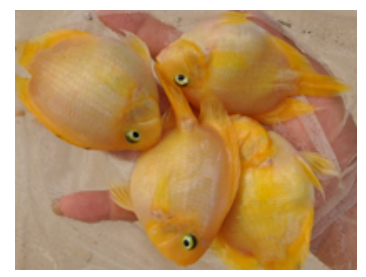

The Control
Figure 4: Digital images of blood parrot from each of the seven diet treatments after 56 days feeding: (Before feeding) original color of fish before feeding pigments (also showing sampling areas for color measurements (1) where all measurements were taken on the same side for all of the fish used in the experiment (side shown in image); (PO) Paprika oleoresin; (HP) H. pluvialis (PR) Phaffia rhodozyma; (AS) astaxanthin; (CA) $\beta$-carotene; (POL) paprika oleoresin + lutein; (The control) the control without any pigments.

and total carotenoids in AS fish skin was also significantly higher than that in CA fish skin $(P<0.05)$.

The correlation between pigments in diet and pigments in scale and skin of fish had also been shown in Table 2. Regression analysis showed that skin $\beta$-carotene levels were significantly correlated with diet $\beta$-carotene $(R=0.91)$ and total carotenoids dose $(R=0.84)$. Scale $\beta$-carotene levels were also correlated with $\operatorname{diet} \beta$-carotene $(R=0.59)$ and total carotenoids dose $(R=0.53)$. Both lutein in scale and skin were linearly related to diet lutein level, with $\mathrm{R}$ values of 0.69 and 0.68 , respectively. Zeaxanthin in skin was correlated with the dietary dose of zeaxanthin $(R=0.56)$, while that in scale was correlated with the dietary dose of lutein $(R=0.53)$. Bothastaxanthin in scale and skin were significantly linearly related to the astaxanthin in the diets, with $R$ values of 0.98 and 0.95 , respectively.

\section{Effects of diet pigments on fish antioxidant parameters}

SOD value of the control fish was significantly higher than that of other fish groups $(\mathrm{P}<0.05)$ (Table 4). The control fish had the highest GSH-P $\mathrm{x}$ and LPO activities, but the lowest T-AOC activity in all fish fed on pigmented diets $(\mathrm{P}<0.05)$. GSH-Px of fish fed on POL diet was the significantly lower than that of fish fed on other experiment diets
$(\mathrm{P}<0.05)$. T-AOC value of fish fed $\mathrm{POL}$ diet was significantly lower than that of fish fed PO, HP, PR and AS diets $(\mathrm{P}<0.05)$. The T-AOC value of CA fish was significantly lower than that of $\mathrm{PR}$ and AS fish (P $<0.05)$. POL fish had significantly lower LPO value than all other fish groups $(\mathrm{P}<0.05)$, followed by AS fish group $(\mathrm{P}<0.05)$. LPO values of $\mathrm{PO}, \mathrm{HP}, \mathrm{PR}$ and CA fish were significantly higher than those of POL and AS fish $(\mathrm{P}<0.05)$.

\section{Discussion}

Paprika oleoresin (also known as paprika extract) is an oilsoluble extract from the fruits of Capsicum annum Linn or Capsicum frutescens (Indian red chillies), and is primarily used as a coloring and/or flavoring in food products. It is composed of capsanthin and capsorubin, the main coloring compounds (among other carotenoids) [11]. Based on the information from paprika oleoresin supplier, capsanthin and capsorubin in paprika oleoresin is about $8 \%$. Although capsanthin and capsorubin contents had not been detected in the trial, total concentration of capsanthin and capsorubin in diet PO and POL would be $32000 \mu \mathrm{g} / 100 \mathrm{~g}$ and $16000 \mu \mathrm{g} / 100 \mathrm{~g}$, theoretically. PO diet did not significantly improve body color in this trial. It is suggesting that capsanthin and capsorubin have no effective contribution on improving body color of blood parrot at least under their current contents in diets.

On the other hand, it could be seen that $a^{\star}$ and $b^{\star}$ of PO fish group had no difference with time, they kept the same level from the beginning to the end of trial (Figures 2 and 3). While POL diet made fish yellower than all other diets since day 35 to the end of trial. The difference between PO and POL diet was with or without lutein adding in diets. It is suggested that it is lutein but not zeaxanthin that turn blood parrot yellow effectively Meyers \& Chen [12]. Classified the aquatic animals into 3 categories by their ability of converting carotenoids into astaxanthin. Type I: salmonoids or sea bream type, which cannot oxidize $\beta$-ionone of the carotenoid and can only use the oxidized carotenoid. Type II: carp type, which can use and convert

\begin{tabular}{|c|c|c|}
\hline Items & Correlation & Regression models \\
\hline $\begin{array}{l}L^{*} \text { of fish body by diet } \\
\text { astaxanthin }\end{array}$ & $R=-0.53, \mathrm{P}<0.01$ & $Y=59.36-0.004 X, R^{2}=0.29$ \\
\hline $\begin{array}{l}a^{*} \text { of fish body by diet } \\
\text { astaxanthin }\end{array}$ & $R=0.91, \mathrm{P}<0.01$ & $Y=-0.44+0.01 X, R^{2}=0.82$ \\
\hline$b^{*}$ of fish body by diet lutein & $R=0.52, \mathrm{P}<0.01$ & $Y=20.82+0.01 X, R^{2}=0.27$ \\
\hline $\begin{array}{l}L^{*} \text { of fish body by } \\
\text { astaxanthin in skin }\end{array}$ & $R=-0.54, \mathrm{P}<0.01$ & $Y=59.13-0.01 X, R^{2}=0.29$ \\
\hline $\begin{array}{l}a^{*} \text { of fish body by } \\
\text { astaxanthin in skin }\end{array}$ & $R=0.91, \mathrm{P}<0.01$ & $Y=0.24+0.03 X, R^{2}=0.83$ \\
\hline $\begin{array}{l}a^{*} \text { of fish body by } \\
\text { astaxanthin in scale }\end{array}$ & $R=0.85, \mathrm{P}<0.01$ & $Y=-2.31+0.25 X, R^{2}=0.72$ \\
\hline $\begin{array}{c}\beta \text {-carotene in skin by diet } \\
\beta \text {-carotene }\end{array}$ & $R=0.91, \mathrm{P}<0.051$ & $Y=1.96+0.02 X, R^{2}=0.83$ \\
\hline $\begin{array}{c}\beta \text {-carotene in scale by diet } \\
\beta \text {-carotene }\end{array}$ & $R=0.59, \mathrm{P}<0.01$ & $Y=3.073+0.004 X, R^{2}=0.35$ \\
\hline $\begin{array}{l}\beta \text {-carotene in skin by diet } \\
\text { total carotenoids }\end{array}$ & $R=0.84, \mathrm{P}<0.01$ & $Y=-24.44+0.03 X, R^{2}=0.71$ \\
\hline $\begin{array}{l}\beta \text {-carotene in scale by diet } \\
\text { total carotenoids }\end{array}$ & $R=0.53, \mathrm{P}<0.01$ & $Y=-1.114+0.004 X, R^{2}=0.28$ \\
\hline Lutein in skin by diet lutein & $R=0.69, \mathrm{P}<0.01$ & $Y=397.13+1.31 X, R^{2}=0.48$ \\
\hline Lutein in scale by diet lutein & $R=0.68, \mathrm{P}<0.01$ & $Y=30.19+0.20 X, R^{2}=0.46$ \\
\hline $\begin{array}{l}\text { Zeaxanthin in skin by diet } \\
\text { zeaxanthin }\end{array}$ & $R=0.56, \mathrm{P}<0.01$ & $Y=171.76+0.21 X, R^{2}=0.31$ \\
\hline $\begin{array}{l}\text { Zeaxanthin in scale by diet } \\
\text { lutein }\end{array}$ & $R=0.53, \mathrm{P}<0.01$ & $Y=15.51+0.03 X, R^{2}=0.28$ \\
\hline
\end{tabular}

Table 2: Regression models of coloration efficacy and regression models of deposition efficacy for each pigment in skin and scale of fish. 


\begin{tabular}{|c|c|c|c|c|c|c|c|c|}
\hline & \multirow{2}{*}{$\begin{array}{l}\text { Carotenoids } \\
(\mu \mathrm{g} / 100 \mathrm{~g})\end{array}$} & \multicolumn{7}{|c|}{ Diet notation } \\
\hline & & HP & PR & AS & CA & POL & The control & PO \\
\hline \multirow{5}{*}{ scale } & $\beta$-carotene & I & $2.67 \pm 1.28^{a}$ & $0.76 \pm 0.23^{a}$ & $25.88 \pm 6.32^{b}$ & $15.74 \pm 5.96^{\mathrm{ab}}$ & $1.98 \pm 0.51^{\mathrm{a}}$ & $1.64 \pm 0.74^{a}$ \\
\hline & Lutein & $35.90 \pm 2.50^{a}$ & $42.07 \pm 5.87^{\mathrm{a}}$ & $34.44 \pm 3.64^{a}$ & $45.03 \pm 6.98^{a}$ & $220.83 \pm 30.15^{\mathrm{b}}$ & $50.18 \pm 5.46^{a}$ & $42.99 \pm 2.97^{a}$ \\
\hline & Zeaxanthin & $13.51 \pm 1.14^{a}$ & $20.62 \pm 4.51^{\mathrm{a}}$ & $14.54 \pm 1.85^{a}$ & $23.42 \pm 4.68^{a}$ & $43.40 \pm 6.30^{\mathrm{b}}$ & $17.91 \pm 4.94^{\mathrm{a}}$ & $16.88 \pm 1.37^{a}$ \\
\hline & Astaxanthin & $54.03 \pm 2.97^{c}$ & $62.61 \pm 3.02^{\mathrm{d}}$ & $74.71 \pm 4.28^{\mathrm{e}}$ & $11.03 \pm 1.29^{b}$ & $15.22 \pm 1.37^{\mathrm{b}}$ & $2.54 \pm 0.07^{a}$ & $14.32 \pm 1.12^{\mathrm{b}}$ \\
\hline & Total carotenoid & $103.44 \pm 5.22^{\mathrm{ab}}$ & $126.78 \pm 9 .{ }^{4} 1 b$ & $123.86 \pm 7.42^{\mathrm{b}}$ & $105.37 \pm 11.46^{\mathrm{ab}}$ & $295.20 \pm 37.97^{c}$ & $72.60 \pm 6.38^{a}$ & $69.78 \pm 6.46^{\mathrm{a}}$ \\
\hline \multirow{4}{*}{ skin } & $\beta$-carotene & $2.09 \pm 0.19^{a}$ & $3.99 \pm 0.51^{\mathrm{a}}$ & $2.40 \pm 0.56^{a}$ & $136.54 \pm 19.74^{b}$ & $7.00 \pm 2.46^{a}$ & $2.24 \pm 0.25^{\mathrm{a}}$ & $1.74 \pm 0.17^{a}$ \\
\hline & Lutein & $437.56 \pm 56.43^{a b}$ & $467.89 \pm 35.97^{a b}$ & $470.33 \pm 54.65^{a b}$ & $629.89 \pm 34.45^{b}$ & $1697.33 \pm 170.57^{c}$ & $266.78 \pm 30.94^{a}$ & $639.89 \pm 77.48^{b}$ \\
\hline & Zeaxanthin & $156.86 \pm 21.54^{a}$ & $187.11 \pm 13.17^{\mathrm{ab}}$ & $152.84 \pm 20.31^{\mathrm{a}}$ & $238.89 \pm 8.97^{b}$ & $378.89 \pm 41.28^{c}$ & $217.78 \pm 21.95^{\mathrm{ab}}$ & $168.13 \pm 23.62^{a b}$ \\
\hline & Astaxanthin & $239.62 \pm 17.23^{b}$ & $496.88 \pm 18.06^{c}$ & $749.93 \pm 24.44^{d}$ & $12.73 \pm 0.44^{\mathrm{a}}$ & $19.47 \pm 0.78^{\mathrm{a}}$ & $3.72 \pm 0.22^{\mathrm{a}}$ & $15.77 \pm 1.5^{4} a$ \\
\hline
\end{tabular}

Note: Data are mean \pm SD. Means not bearing the same superscript letters in the same row are significantly different $(P<0.05)$.

Table 3: Carotenoids content in the scale and skin of blood parrot after being fed for 56 days

\begin{tabular}{|c|c|c|c|c|c|c|c|}
\hline \multirow{2}{*}{ Antioxidant parameter } & \multicolumn{7}{|c|}{ Diet notation } \\
\hline & PO & HP & PR & AS & CA & POL & The control \\
\hline SOD (U/ml) & $59.04 \pm 1.23^{a}$ & $58.13 \pm 1.13^{a}$ & $59.72 \pm 0.74^{a}$ & $61.37 \pm 1.18^{a}$ & $59.52 \pm 1.25^{\mathrm{a}}$ & $58.18 \pm 0.57^{a}$ & $66.02 \pm 1.18^{b}$ \\
\hline GSH-Px (U/ml) & $1033.6 \pm 14.2^{\mathrm{b}}$ & $1025.0 \pm 21.8^{b}$ & $1055.1 \pm 19.3^{b}$ & $1065.9 \pm 13.7^{b}$ & $1059.2 \pm 7.6^{b}$ & $931.1 \pm 46.6^{a}$ & $1293.4 \pm 10.4^{c}$ \\
\hline T-AOC (U/ml) & $12.40 \pm 0.43^{\mathrm{cd}}$ & $12.24 \pm 0.36^{\mathrm{cd}}$ & $12.69 \pm 0.24^{d}$ & $12.72 \pm 0.29^{d}$ & $11.39 \pm 0.69^{b c}$ & $10.44 \pm 0.37^{b}$ & $9.14 \pm 0.32^{\mathrm{a}}$ \\
\hline LPO (nmol/ml) & $37.06 \pm 2.90 c$ & $39.43 \pm 1.67^{c}$ & $36.83 \pm 1.47^{c}$ & $23.21 \pm 1.74^{b}$ & $36.71 \pm 2.58^{c}$ & $15.67 \pm 1.04^{a}$ & $50.57 \pm 3.98^{d}$ \\
\hline
\end{tabular}

Note: Data are mean \pm SD. Means not bearing the same superscript letters in the same row are significantly different $(P<0.05)$.

Table 4: Main effects of dietary carotenoid concentration on activity of antioxidants in blood parrot after 56 days feeding trial.

zeaxanthin into astaxanthin and store astaxanthin. Type III: crustacean type, which can convert $\beta$-carotene, zeaxanthin, canthaxanthin, and echinenone into astaxanthin. As one of carp types, common goldfish had been proved the ability to convert lutein to astaxanthin from the result of feeding $\left[{ }^{14} \mathrm{C}\right]$ lutein to the yellow variety [13]. Salmonids preferentially absorb and deposit more polar carotenoids, particularly astaxanthin, rather than canthaxanthin, zeaxanthin, or carotenes $[14,15]$ indicated that rainbow trout (Oncorhynchus mykiss) could deposit more astaxanthin than $\beta$-carotene, a condition that could result from differences in absorption, tissue distribution, and retention. Our results coincide with these findings. In this trial, although lutein, zeaxanthin and $\beta$-carotene had been transport from diets and deposit in skin and scale because their content in skin and scale were lineal correlated with them in diet, it seemed that lutein, $\beta$-carotene and zeaxanthin in diet had no significant contribution to body red color or astaxanthin concentration in diet, skin and scale. Regression analysis of $a^{\star}$ revealed that $a^{*}$ is just linearly related to astaxanthin in diet, skin and scale, respectively, whilst astaxanthin in skin and scale are directly come from diet astaxanthin with significant linear correlation. Above results suggest that astaxanthin is the most efficacious pigment in red pigmentation of blood parrot. The results from this study are suggesting that the type of blood parrot using carotenoids more likely similar with salmonoids or sea bream type.

In this trial, carotenoids in skin and scale are highly coincides with them in diets (Tables 2 and 3). But all flesh samples of blood parrot are colorless and translucent, and none of carotenoids has been tested in all flesh samples. Fish absorb dietary carotenoids through the intestinal mucosa transport them through the blood via serum lipoproteins [16] and deposit them into specialized skin cells called chromatophores [17]. Apparently, blood parrot deposits carotenoids into skin and scale instead of flesh to keep its body color as effective as possible [18].

As body color is the major factor influencing the commercial value of blood parrot, it is therefore becoming important to enhance body red color as soon as possible. In general, it is the sooner the better. So the time of getting red is very crucial, too. In the present trial, body color parameters were measured every week in order to find out which pigment will turn fish red more quickly. This was most apparent after 7 days of feeding, when red chromaticity $a^{*}$ values of AS fish group were significantly higher than other fish groups and red coloration continued to increase until 56 days of feeding on the AS diet. After being fed 14 days, PR fish group got significantly higher $a^{*}$ values than the control fish group and kept this advantage until the end of the trial, too. The third one was HP fish group from 21 days to the end of the trial. The time of getting red also fits in with astaxanthin concentration in diet.

According above results, the intensity and time of getting red are strongly according with diet astaxanthin concentration. The more astaxanthin in diet, the more and sooner fish body will get red. It seems that PR and HP fish group would get the same $a^{\star}$ level if more $P$. rhodozyma or $H$. pluvialis were added into diet to reach the same astaxanthin concentration with AS diet. However, although commercial price of synthetic astaxanthin is about 3 times over of $P$. rhodozyma and $H$. pluvialis, its dosage is just one fifth of the latter pair. On turning blood parrot to red, synthetic astaxanthin will be more commercially competitive than natural astaxanthin sources from $P$. rhodozyma and $H$. pluvialis.

Lightness $L^{\star}$ of AS fish group was the lowest from 21 day feeding to the end of trial. It might be associated with their dark red appearance. The lightness of fish body decreased with the increasing of redness. This is in accord to Baron [19] who found that the skin of flame-red dwarf gourami (Colisa lalia) became darker when fed synthetic astaxanthin Lucantin Pink. It can be seen that $L^{*}, a^{*}$ and $b^{*}$ of the control fish decreased with the time increasing, and their values are significantly lower at the end of trial compared with those at the beginning of the trial. There is not any pigments supply in the control diet will be the reason of fish fading. This result confirmed that pigments need add in blood parrot feed to make fish keeping good body color in actual production.

Owing to their structure, carotenoids possess free radical scavenging properties and therefore act as antioxidants. This has been demonstrated in both in vivo and in vitro systems, as well as in studies using membrane models [20-22]. SOD, a cytosolic enzyme that is 
specific for scavenging superoxide radicals, is involved in protective mechanisms within tissue injury following oxidative process and phagocytosis. The higher the SOD activity, the more superoxide radicals need to be reacted [23]. It was found that characins (Hyphessobrycon callistus) [23]. And olive flounder (Paralichthys olivaceus) [24] fed on carotenoid diets had lower SOD activities than fish fed the control diet. In this study, lower SOD activity of fish fed dietary carotenoids indicated that dietary carotenoid effectively reduced SOD activity in blood parrot.

GSH-Px exists in blood, liver, mitochondria, and cytoplasm and involves in the reaction of removal of $\mathrm{H}_{2} \mathrm{O}_{2}$ and is recognized as one of the most important antioxidant defenses against oxygen toxicity in organisms. The lower the GSH-Px value, the higher protection that cell has already been provided and reported $[25,26]$ that much lower GSHPx in characins fed on pigmented diets than that in control fish and the decreasing trend of GSH-Px with increasing dietary astaxanthin and $\beta$-carotene concentration. Our results are in accordance with previous findings. Carotenoid sources significantly decreased plasma GSH-Px activities of blood parrot. And the lowest GSH-Px activities of fish fed POL diet might be due to its extremely high total carotenoid concentration (Table 3). It is suggesting that carotenoids could reduce peroxide in cells and concomitantly the GSH-Px effectively, and their efficiency might be positively related with their concentration. The antioxidant capacity that T-AOC expresses includes enzymatic and non-enzymatic antioxidant activities. The higher T-AOC value, the higher antioxidant capacity it has [23]. In this study, all carotenoid diets were significantly higher than the control diet. It means that these carotenoids can improve antioxidant capacity of blood parrot effectively.

LPO is decomposed into a variety of oxygen-containing redicals. The resulting radicals attack almost all cell components, such as proteins, lipids, nucleic acids and membranes, initiate free radical chain reactions, and induce oxidative stress [27]. The serum LPO level is considered to be one of the sensitive indicators of tissue damage derived from oxidative stress [28]. The higher LPO level in serum, the more tissue damage derived from oxidative stress. LPO production in serum and muscle were observed to be significantly decreased after the red yeast administration [29]. Our research confirmed their results. In the present study, the plasma LPO of fish fed the control diet was observed to be significantly higher than that of all carotenoids diets $(\mathrm{P}<0.05)$. POL and AS diets were shown more effectively inhibit the accumulation of LPO in plasma than the rest of carotenoids diets. These results suggest that all carotenoids in this study reduce the LPO level in blood parrot dramatically, and their efficiency maybe positively related with their concentration, too.

In conclusion, blood parrot is able to efficiently utilize synthetic and natural astaxanthin supplied in the diets. Deposit is mainly done in its skin and scale, which causes an acceptable red-colored natural color. All test carotenoid source could increase antioxidant activities of blood parrot effectively.

\section{Acknowledgements}

This work was financially supported by Beijing Innovation Consortium of The Ornamental Fish Research System, project No. GSY20160204.

\section{References}

1. Yang $H, M u X$, Luo D, Hu Y, Song $H$, et al. (2012) Sodium taurocholate, a novel effective feed-additive for promoting absorption and pigmentation of astaxanthin in blood parrot (Cichlasoma synspilum $q \times$ Cichlasoma citrinellum J). Aquaculture 350-353: 42-45.
2. Goodwin T (1984) The Biochemistry of Carotenoids, vol II, Chapman and Hall, London, UK

3. Shahidi F, Metusalach A, Brown J (1998) Carotenoid pigments in seafoods and aquaculture. Crit Rev Food Sci Nutr 38: 1-67.

4. Kalinowski C, Robaina L, Fernandez-Palacios H, Schuchardt D, Izquierdo M, et al (2005) Effect of different carotenoid sources and their dietary levels on red porgy (Pagrus pagrus) growth and skin colour. Aquaculture 244: 223-231.

5. Gouveia, Rema P (2005) Effect of micro algal biomass concentration and temperature on ornamental goldfish (Carassius auratus) skin pigmentation. Aquaculture Nutrition 11: 19-23.

6. Mela M, Smullen R, Obra R (2002) Non-invasive methods for measuring the accumulation of carotenoids in common goldfish (Carassius auratus) fed by astxanthin, canthaxanthin and lutein supplemented diet. In: Proceedings of the $10^{\text {th }}$ international symposium on Nutrition and Feeding in Fish.

7. Tejera N, Cejas J, Rodríguez C, Bjerkeng B, Jerez S, et al. (2007) Pigmentation carotenoids, lipid peroxides and lipid composition of skin of red porgy (pagrus pagrus) fed diets supplemented with different astaxanthin sources. Aquaculture, 270: $218-230$.

8. Halliwell B, gutteridge J (1989) Free Radicals in Biology and Medicine (2ndedn) Clarendon Press, Oxford, USA.

9. Christinasen R, Torrissen O (1996) Growth and survival of Atlantic salmon Salmo salar $\mathrm{L}$. fed different dietary levels of astaxanthin Juveniles. Aquaculture Nutrition 2: 55-62.

10. Chien Y, Shian W (2005) The effects of dietary supplementation of algae and synthetic astaxanthin on body astaxanthin, survival, growth and low dissolved oxygen stress resistance of kuruma prawn, Marsupenaeus japonicas Bate. Journal of Experimental Marine Biology and Ecology 318: 201-211.

11. Pérez-Gálvez, A, Martin H, Sies H, Stahl W (2003) Incorporation of carotenoids from paprika oleoresin into human chylomicrons. Br J Nutr 89: 787-793.

12. Meyers S, Chen $\mathrm{H}$ (1982) Astaxanthin and its role in fish culture. Proceedings of the Warm water Fish Culture Workshop. Spec. Publ 3: 153-165.

13. Hsu W, Rodriguez D, Chichester C (1972) The biosynthesis of astaxanthin. VI. The conversion of $\left[{ }^{14} \mathrm{C}\right]$ lutein and $\left[{ }^{14} \mathrm{C}\right] \beta$-carotene in goldfish. Int $\mathrm{J}$ Biochem 3: 333-338.

14. Schiedt K, Leuenberger M, Vecchi M, Glinz E (1985) Absorption, retention and metabolic transformations of carotenoids in rainbow trout, salmon, and chicken. Pure Appl Chem 57: 685-692.

15. Amar E, Kiron V, Satoh S, Watanabe T (2004) Enhancement of innate immunity in rainbow trout (Oncorhynchus mykiss Walbaum) associated with dietary intake of carotenoids from natural products. Fish and Shellfish Immuno 16: $527-537$.

16. Bowen J, Soutar C, Serwata R, Lagocki S, White D, et al. (2002) Utilization of (3S, 3'S)-astaxanthin acyl esters in pigmentation of rainbow trout (Oncorhynchus mykiss). Aqua Nutr 8: 59-68.

17. Chatzifotis S, Pavlidis M, Donate J, Vardanis G, Sterioti A, et al. (2005) The effect of different carotenoid sources on skin coloration of cultured red porgy (Pagrus pagrus). Aqua research 36: 1517-1525.

18. Furr H, Clark R (1997) Inestinal absorption and tissue distribution of carotenoids Journal of Nutritional Biochemistry 8: 364-377.

19. Baron M, Davies S, Alexander L, Snellgrove D, Sloman K, et al. (2008) The effect of dietary pigments on the coloration and behavior of flame-red dwarf goruami, Colosa lalia. Anl behavior 75: 1041- 1051.

20. Kennedy T, Liebler D (1992) Peroxy adical scavenging by $\beta$-carotene in lipid bi-layers: effect of oxygen partial pressure. J Biol Chem 267: 4658-4663.

21. Nakagawa K, Fujimoto K, Miyazawa T (1996) $\beta$-Carotene as a high potency antioxidant to prevent the formation of phospholipid hydroperoxides in red blood cells of mice. Biochimica et Biophysica Acta 1299:110-116.

22. Someya K, Totsuka Y, Murakoshi M, Kitano H, Miyazawa T, et al. (1994) The antioxidant effect of palm fruit carotene on skin lipid peroxidation in guinea pigs as estimated by chemiluminescence-HPLC method. J Nutr Sci Vitaminol 40 : 315-324.

23. Wang Y, Chien Y, Pan C (2006) Effects of dietary supplementation of carotenoids on survival, growth, pigmentation, and antioxidant capacity of characins, Hyphessobrycon callistus. Aquaculture 261: 641-648. 
Citation: Li T, He C, Ma Z, Xing W, Jiang N, et al. (2016) Effects of Different Carotenoids on Pigmentation of Blood Parrot (Cichlasoma synspilum $\times$ Cichlasoma citrinellum). J Aquac Res Development. 7: 414. doi:10.4172/2155-9546.1000414

24. Pham K, Byun H, Kim K, Lee S (2014) Effectsof dietary carotenoid source and level on growth, skin pigmentation, antioxidant activity and chemical composition of juvenile olive flounder Paralichthys olivaceus. Aquaculture 431 65-72.

25. Kappus $\mathrm{H}$, Sies $\mathrm{H}$ (1981) Toxic drug effects associated with oxygen metabolism, redox cycling and lipid peroxidation. Experientia 37: 1233-1241.

26. Cohen G, Doherty M (1987) Free radical mediated cell toxicity by redox cycling chemicals. British J Cancer 55: 46-52.
27. Aoshima H, Satoh T, Sakai N, Yamada M, Enokido Y, et al. (1997) Generation of free radicals during lipid hydroperoxide-triggered apoptosis in PC12h cells. Biochim Biophys Acta 1345: 35-42.

28. Hata Y, Kaneda T, Fukuda H, Mino M (1984) Lipid hydroperoxide and nutrition, Kouseikan, Tokyo, Japan.

29. AOAC (2005) Official Methods of Analysis. (18thedn.) Association of Official Analytical Chemists, Gaithersburg, USA. 